\title{
UN ESTUDIO ACERCA DE LA EVENTUAL DIRECTIVA COMUNITARIA SOBRE EL DERECHO A LA DESCONEXIÓN DIGITAL EN EL TRABAJO ${ }^{1}$
}

\author{
Dr. Francisco Trujillo Pons \\ Profesor Ayudante Doctor de la Universidad de Valencia \\ Departamento de Derecho del Trabajo y de la Seguridad Social
}

\begin{abstract}
Brevemente, el derecho a desconectarse digitalmente en el trabajo se refiere al derecho de los trabajadores a no recibir o contestar ningún correo electrónico, llamada o mensaje relacionado con motivo laboral fuera del horario de trabajo habitual. Si bien el derecho a la desconexión encuentra acomodo en el ordenamiento jurídico español, a nivel comunitario son muchos los países que todavía no cuentan con regulación propia al respecto. Dada la urgencia de la cuestión por la potenciación de los dispositivos digitales provocados por la COVID-19 y el consecuente teletrabajo, el Parlamento Europeo está avanzando en la regulación del derecho a nivel comunitario. En caso de cristalizarse la Directiva comunitaria podría suponer el estímulo definitivo para que el legislador nacional desarrolle de forma más completa y garantista el derecho del trabajador al desenganche tecnológico.
\end{abstract}

Briefly, the right to digitally disconnect at work refers to the right of workers not to receive or reply to any work-related email, call or message outside of normal working hours. Even though the right to disconnect is recognised in the Spanish legal system, at the Community level many countries do not have yet their own regulation in this regard. Given the urgency of the promotion of digital devices due to the COVID-19 pandemic, and the resulting telework, the European Parliament is making progress in regulating the law at the community level. If the Community directive is crystallized, it could be the definitive stimulus for the national legislator to develop in a more complete and guaranteed way the right of the worker to technological disengagement.

Title: A study regarding the possible European Directive regarding the right to disconnect at work.

IUSLabor 1/2021, ISSN 1699-2938, p. 66-96

DOI. 10.31009/IUSLabor.2021.i02.3

Fecha envío: 29.1.2021 | Fecha aceptación: 8.3.2021

\footnotetext{
${ }^{1}$ El presente artículo se enmarca en las líneas de actuación del Grupo de Investigación: Desconexión digital en el trabajo. DesC-Labor (GIUV2020-473) Universitat de València (España).
} 
Palabras clave: Desconexión digital, trabajo, descansos, seguridad, salud, Directiva, Europa, España, comunitario, prevención, psicosocial.

Keywords: Digital disconnection, work, breaks, safety, health, directive, Europe, Spain, community, prevention, psychosocial.

\section{Sumario}

1. Introducción

2. Un paso al frente del legislador comunitario en el derecho a la desconexión digital en el trabajo

3. Estudio de la iniciativa legislativa

4. Conclusiones 


\section{Introducción}

Con carácter previo al estudio y análisis de la iniciativa legislativa del Parlamento Europeo, resulta conveniente hacer hincapié en la actual situación de la pandemia provocada por la COVID-19 y observar el estado de la cuestión de la regulación del derecho de la desconexión digital en la Unión Europea (UE) y los motivos que han desencadenado la iniciativa comunitaria.

Son pocos los países europeos con normativa propia y los que cuentan, como ahora Francia y España, lo hacen con regulaciones más coyunturales que estructurales que exigen ser revisadas y complementadas. El papel de la futura Directiva, en cualquiera de los casos, ayudará a que los países cuenten con normativa propia y los que ya lo hacen, desarrollen sus preceptos a fin de que resulte más garantista y proteccionista para que los trabajadores comunitarios puedan ejercer con plena eficacia su derecho a desconectar sus dispositivos digitales tras su horario de trabajo.

Las herramientas tecnológicas que se utilizan en el ámbito laboral no pueden suponer una barrera al descanso del trabajador. Para garantizar esta máxima, surge un nuevo derecho en el trabajo: el derecho del trabajador a su desconexión digital toda vez ha finalizado su jornada laboral ${ }^{2}$. De este modo, en atención al respeto a su intimidad, conciliación personal y familiar y descanso, fuera del tiempo de trabajo legal o convencionalmente establecido, el trabajador no tiene la obligación de responder a llamadas, correos electrónicos corporativos, ni mensajes de texto.

Un derecho que alcanza su cenit en las nuevas formas de trabajo a distancia. Las empresas han de saber que el trabajo en remoto va a ser parte de la vida de muchos trabajadores. Han de reajustarse y prosperar en la presente era digital, todo en base al bienestar de sus empleados. La cultura ha de estar centrada en este bienestar para que la sensación de estar siempre activo no resulte ser la queja más concurrente en los trabajadores. Lejos de la apariencia de la comodidad que puede haber en el trabajo a distancia, los empleados no están desconectando y no distinguen límites entre tiempo de trabajo y tiempo de descanso. La cultura de la empresa centrada en el bienestar de sus empleados ha de partir siempre en los cargos con responsabilidad, los cuales, deben ser formados en la asertividad y en saber involucrar a sus empleados para que no se agoten y estén descansados. La confianza mutua es clave para que la comunicación entre las partes sea proactiva: si un mando con cargo realiza una comunicación fuera del tiempo de trabajo ha de saber esperar a que su trabajador conteste cuando inicie su jornada de trabajo. Al igual el trabajador que al tener la confianza de su responsable, no va a tener problema alguno en dejar pasar esta

\footnotetext{
${ }^{2}$ Vid. TRUjILlo PONS, Francisco, La desconexión digital en el ámbito laboral, Tirant lo Blanch, 2020.
} 
comunicación hasta que se incorpore al trabajo. Esta cultura de empresa ha de centrarse en el ejercicio del derecho a la desconexión digital. No debe escatimar esfuerzos en dar descansos a sus trabajadores para eliminar o controlar posibles situaciones de estrés mental o fatiga informática. ¿No es posible en la presente era digital dar la posibilidad a que un trabajador con signos de fatiga pueda tomarse un tiempo libre y de descanso para recargar? Es posible pero siempre teniendo en cuenta que cada circunstancia laboral y empresarial es única y no existe una solución general para enfrentarse al desafío del descanso tecnológico de los trabajadores. La empatía y la compasión dependerá de cada empresa, por lo que aquella que esté centrada en el bienestar del empleado redactará políticas internas muy favorables mientras que otra que tienda más a la productividad sin excepción alguna, directamente no adoptará medida alguna.

Se trata de un derecho que ya tiene cabida en países europeos y aunque es novedoso y que aparece por el auge de las Tecnologías de la Información y de la Comunicación (TIC), lo cierto es que se cimenta en normativa comunitaria ya existente y desde todas las aristas relacionadas con la desconexión digital: 1) el derecho al descanso conforme al artículo $31^{3}$ de la Carta de los Derechos Fundamentales de la Unión Europea, de 12 de diciembre de 2007 y la Directiva 2003/88/CE del Parlamento Europeo y del Consejo, de 4 de noviembre de 2003, relativa a determinados aspectos de la ordenación del tiempo de trabajo; 2) el derecho a la seguridad y salud de acuerdo con la Directiva 89/391/CEE del Consejo, de 12 de junio de 1989, relativa a la introducción de medidas para fomentar la mejora de la seguridad y la salud de los trabajadores en el trabajo y la Directiva 91/383/CEE del Consejo, de 25 de junio de 1991, por la que se complementan las medidas para fomentar la mejora de la seguridad y la salud en el trabajo de los trabajadores con una relación laboral de duración determinada o una relación laboral temporal y; 3 ) desde la conciliación de la vida personal y laboral en virtud de la Directiva (UE) 2019/1158 del Parlamento Europeo y del Consejo, de 20 de junio de 2019, sobre el equilibrio entre la vida personal y laboral de los padres y cuidadores.

Adherido a este conjunto normativo de la UE, a nivel internacional la Organización Internacional del Trabajo (OIT) también cuenta con convenios y recomendaciones que casan con el ejercicio del derecho a la desconexión digital, aunque del mismo modo que la UE, no existe ningún convenio o recomendación concreta sobre el derecho. Sea como sea, son destacables desde la OIT, el Convenio sobre las horas de trabajo (industria) de 1919 (núm. 1), el Convenio sobre las horas de trabajo (comercio y oficinas) de 1930 (núm. 30), la Recomendación sobre la negociación colectiva de 1981 (núm. 163), el Convenio

\footnotetext{
3 "Artículo 31 Condiciones de trabajo justas y equitativas

1. Todo trabajador tiene derecho a trabajar en condiciones que respeten su salud, seguridad y dignidad.

2. Todo trabajador tiene derecho a la limitación de la duración máxima del trabajo y a períodos de descanso diarios y semanales, así como a un período de vacaciones anuales retribuidas".
} 
sobre los trabajadores con responsabilidades familiares de 1981 (núm. 156) y la Recomendación que la acompaña (núm. 165), así como la Declaración del centenario de la OIT sobre el futuro del trabajo de 2019.

Es cierto que, en la actualidad, se difuminan los tiempos de trabajo efectivo y de descanso. A fin de evitar confusión, la citada Directiva 2003/88/CE realiza la siguiente definición del tiempo de trabajo "todo período durante el cual el trabajador permanezca en el trabajo, a disposición del empresario y en ejercicio de su actividad o de sus funciones, de conformidad con las legislaciones y/o prácticas nacionales". Es importante conocer este extremo para contextualizar el plus de disponibilidad según el cual, el trabajador no disfrutaría del derecho a la desconexión digital fuera de su jornada laboral.

Este derecho tiene su surgimiento en Francia, en 2016, cuando se promulgó la Ley $\mathrm{n}^{\circ}$ 2016-1088, de 8 de agosto de 2016 (conocida como "El Khomri"). relativa al trabajo, a la modernización del diálogo social y al aseguramiento de los recorridos profesionales. De forma innovadora regula el derecho de todos los trabajadores a la desconexión digital ("Droit à la déconnexion") otorgando un papel fundamental a las empresas en la definición de los entornos y de los límites a través de un acuerdo colectivo o, en su defecto, mediante un estatuto. Esta Ley nace tanto de la experiencia convencional como de la existencia de informes que inspiraron en gran medida su contenido. Tal y como se aprecia, el derecho se modula por la negociación colectiva, brindando, de este modo una autonomía muy importante a las empresas para que adapten a la desconexión digital a su cultura organizacional y a sus empleados. Igualmente, el legislador francés obliga a las empresas de más de 50 empleados a negociar el derecho con la representación laboral. Al igual que sucede en España, la legislación gala no precisa su contenido, remitiéndose al efecto a la negociación colectiva quien debe definir la puesta en marcha por la empresa de regulación de la utilización de los dispositivos digitales. Más reciente en el tiempo y producto de la pandemia mundial y la potenciación mundial del teletrabajo, Francia con fecha de 26 de noviembre de 2020 firmó un acuerdo de teletrabajo con los agentes sociales donde se refuerza el derecho a la desconexión digital ${ }^{4}$ aunque lejos de un mayor desarrollo y concreción.

\footnotetext{
${ }^{4}$ Específicamente en su apartado 3.1.3. rubricado como "Control de la jornada laboral, respeto al derecho a desconectar y a la intimidad" de cuyo tenor literal es el siguiente: "Las disposiciones del Código del Trabajo requieren que el empleador controle la duración del trabajo del empleado. El empleador fija, en consulta con el empleado, los intervalos de tiempo durante con el que pueda contactar, de acuerdo con el horario laboral vigente en el negocio. De las disposiciones legales se desprende que, si un medio de controlar la actividad del empleado y el control del tiempo de trabajo está en su lugar, debe estar justificado por la naturaleza de la tarea a realizar y proporcionada al objetivo buscado, y el empleado debe ser informado. La implementación de dispositivos digitales específicos requiere el cumplimiento de dos condiciones acumulativas: consulta previa al CSE e información previa empleados. La implementación del teletrabajo tiene en cuenta el derecho a desconectarse, que debe ser objeto de un acuerdo o una carta
} 
Desde entonces, y tras la iniciativa francesa, Bélgica un país con una influencia muy próxima a Francia, reguló el derecho por medio de la Ley de 5 de marzo de 2017 "Loi concernant le travail faisable et maniable" mediante una serie de preceptos relacionados con el tiempo de trabajo y los choques digitales que pueden desequilibrar los intereses de los trabajadores ${ }^{5}$. Después Italia legisló también en este sentido conforme a la Legge 22 maggio 2017, n. ${ }^{\circ} 81$ (vigente desde el 14 de junio de 2017) tocante a medidas de tutela del trabajo autónomo y medidas para favorecer una articulación flexible del tiempo y lugar de trabajo por cuenta ajena, incorpora un precepto, rubricado como trabajo ágil como forma de desempeño de la actividad flexible donde se alterna la presencia física en la empresa con el trabajo a distancia y, dado que esta forma de trabajo incorpora múltiples herramientas tecnológicas, impera el derecho de los trabajadores italianos a que se repete su tiempo de descanso y se ordena acordar la desconexión del empleado de dichas TICs.

Luego desde Asia, India, tomando como ejemplo claro la regulación gala, promulgó en enero de 2018 la Ley “The right to disconnect Bill, 2018” núm. 211 que le confiere a cada empleado la libertad de desprenderse de las redes comunicacionales que lo vinculan con su trabajo, es decir, correos electrónicos o llamadas telefónicas, durante las horas fuera del horario y en las vacaciones ${ }^{6}$. La Ley, determina de forma clara el derecho del empleado a "negarse a responder llamadas fuera del trabajo" sobre cualquier materia relacionada a su prestación de servicios.

En lo que respecta a España, en términos normativos, el derecho queda regulado primero por medio de la Ley Orgánica 3/2018, de 5 de diciembre, de Protección de Datos Personales y Garantía de los Derechos Digitales (LOPDPGDD), la cual conforme a su artículo 88, modifica entre otras disposiciones legales, el Estatuto de los Trabajadores (ET), con la inclusión de un nuevo artículo, el 20 bis y, segundo y más reciente por medio del artículo 18 del Real Decreto-ley 28/2020, de 22 de septiembre, de trabajo a distancia

sobre sus métodos de implementación, en las condiciones previstas por las disposiciones del Código del Trabajo relativas a negociación obligatoria en los negocios. El objetivo del derecho a desconectar es el respeto por los períodos de descanso y licencias, así como por la vida personal y familiar del empleado. Es el derecho de cualquier empleado a no estar conectado a una herramienta digital profesional fuera del horario laboral. El empleador organizará una entrevista anual que se centrará en las condiciones de trabajo y carga de trabajo del trabajador a distancia".

5 Service public fédéral Emploi, Travail et Concertation sociale - Loi concernant le travail faisable et maniable, de 15 de marzo de 2017, recuperado de (fr): https://emploi.belgique.be/fr/actualites/loiconcernant-le-travail-faisable-etmaniable\#: :text=La\%201oi\%20du\%205\%20mars,le\%20travail\%20faisable\%20et\%20maniable.

[Consulta a 29 enero de 2021].

6 Bill No. 211 of 2018. THE RIGHT TO DISCONNECT BILL, 2018. Recuperado de: http://164.100.24.219/billstexts/LSBillTexts/AsIntroduced/2317as.pdf [Consulta a 27 septiembre de 2020]. 
(RDLTD). De esta forma, desde el 7 de diciembre de 2018 existe en España ${ }^{7}$ un derecho laboral propio de la presente era digital y que supone una garantía para que el trabajador pueda descansar de la tecnología laboral fuera de su horario de trabajo. Son muchos los trabajadores que desarrollan su trabajo en horas libres y reciben $e$-mails o llamadas de trabajo cuando deberían estar descansando y conciliando su vida personal y familiar. Así, con telón de fondo en el uso intensivo de las TIC se reconoce el derecho del trabajador a la desconexión digital en el ámbito laboral como parte del derecho a la intimidad en el uso de dispositivos digitales como teléfonos móviles inteligentes (smartphones), ordenadores, relojes inteligentes (smartwatches), tablets, etc. En consecuencia, las empresas tanto públicas como privadas con independencia de su plantilla tienen para sus trabajadores que presten servicios tanto en centros de trabajo físicos como en remoto o a distancia, la obligación de establecer una política interna sobre las modalidades del ejercicio del derecho a la desconexión digital en el ámbito laboral, previa audiencia de los representantes de los trabajadores. Del mismo modo, el legislador hace un llamamiento a la negociación colectiva para que las partes, determinen en los convenios colectivos las distintas modalidades de la desconexión digital. Como se aprecia, es un derecho flexible y autorregulable amoldable a cada puesto de trabajo y sector de actividad.

\footnotetext{
${ }^{7}$ Ciertamente es un país concienciado en este nuevo derecho laboral que va a tener un impacto inmediato y en el futuro. La desconexión digital ligada a la dignidad de la persona se trata de un derecho inviolable. El intenso progreso de la investigación científica, las invenciones y las tecnologías digitales o basadas en lo digital es tan significativo que desde el Gobierno español se está planteando la elaboración de una Carta de Derechos Digitales (el plazo de consulta pública finalizó el 20 de enero de 2021) a fin de asegurar que el marco normativo garantiza la protección de los derechos individuales y colectivos de las personas. Muchos trabajadores dependen de la sociedad digital actual compuesta de entornos, dispositivos y servicios. El ordenamiento jurídico ha de modernizarse para garantizar y promocionar los derechos laborales desde la vertiente tecnológica. La Carta de Derechos Digitales se refuerza en el documento elaborado por el Gobierno español "España Digital 2025" en el que una de las metas a alcanzar es el de garantizar los derechos de la ciudadanía en el nuevo entorno digital (meta 2025: una carta nacional sobre derechos digitales). En esta Carta se dedica en su apartado XVII los derechos reconocidos a todos los trabajadores y empleados públicos en el ámbito laboral entre ellos, la desconexión digital; la protección de su intimidad en el uso de dispositivos digitales puestos a su disposición por su empleador, así como frente al uso de dispositivos de videovigilancia y de grabación de sonidos en el lugar de trabajo y; la intimidad ante la utilización de sistemas de geolocalización. Destacando a continuación que en todo caso se garantizarán condiciones de trabajo digno en los entornos digitales. La Carta apuesta por promover el acceso al teletrabajo cuando la naturaleza del puesto y las capacidades de la organización lo permitan. Y cuando así sea, la prestación laboral se ha de desarrollar con pleno respeto a la dignidad del trabajador garantizando particularmente su derecho a la intimidad, la esfera privada del domicilio, los derechos de las personas que residen en él y el derecho a la conciliación de la vida personal y familiar. De ahí la importancia de los convenios colectivos y protocolos de actuación y políticas de desconexión que determinen adecuadamente los instrumentos medidas y herramientas que garanticen y protejan estas esferas inherentes de la persona.
} 
En suma, el legislador español de forma expresa desarrolla en su normativa la desconexión digital de los trabajadores en el ámbito laboral. Antes de su aparición a finales de 2018 no existía ni normativa ni, evidentemente cuerpo de doctrina judicial como tal. Y ello porque esta materia, al igual que sucede en Francia, se ha venido dejando a la capacidad de autorregulación de las partes; bien a nivel de pactos individuales (contratos de trabajo) o, de forma preferente, a nivel colectivo por medio de convenios colectivos, acuerdos extra estatutarios o protocolos de actuación empresarial.

\section{Un paso al frente del legislador comunitario en el derecho a la desconexión digital en el trabajo}

La pandemia de la COVID-19 ha determinado el auge del trabajo a distancia a nivel comunitario. Una modalidad de trabajo que en opinión -atinada- de los eurodiputados difumina la línea que separa la vida personal y profesional de los trabajadores. Y ello debido a que los dispositivos digitales como son los teléfonos móviles u ordenadores pueden abocar a que, directa o indirectamente, permanezcan en constante contacto con sus empresas.

Son indudables los graves perjuicios que pueden sufrir los trabajadores debido a la rápida e inaudita conectividad permanente que están experimentando en sus trabajos: lejos de descansar, siguen trabajando constantemente. Esta conexión constante y la consecuente falta de desenganche tecnológico, aboca a la aparición de riesgos psicosociales y ergonómicos en los trabajadores. Más en este sentido, aparecen determinados trabajos que años atrás eran impensables y de los que el legislador comunitario ha de regular convenientemente para aportar seguridad jurídica a los trabajadores. Así, se hace patente un fenómeno muy extendido conocido como "always on ", es decir, trabajos cuyas características permiten la disponibilidad absoluta del trabajador tanto de forma horaria como locativa.

Se patentiza así la aparición de situaciones de estrés y de fatiga informática surgidos ante usos excesivos de las TIC; de ahí la necesidad de que los trabajadores tengan el derecho a desconectar digitalmente y así no estar disponibles una vez termina la jornada laboral, en días de descanso o en periodos vacacionales. Se trata de un derecho que debe ser ejercido con plenas garantías máxime por la potenciación de los trabajos a distancia derivados de la COVID-19. Pandemia mundial que ha empujado a muchos a realizar su prestación de servicios mediante la modalidad del teletrabajo mediante el uso exclusivo o prevalente de medios y sistemas informáticos, telemáticos y de telecomunicación. En

\footnotetext{
8 Vid. Serrano ArgüESo, Mariola, “Always on”. Propuestas para la efectividad del derecho a la desconexión digital en el marco de la economía 4.0”, Revista Internacional y Comparada de Relaciones Laborales y Derecho del Empleo, 7, vol. 2, 2019, p. 164-191.
} 
estos contextos la disponibilidad de los dispositivos electrónicos móviles es cada vez mayor al facilitar la realización del trabajo desde cualquier sitio y en cualquier momento.

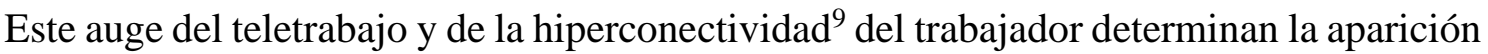
de riesgos laborales muy preocupantes. Estos daños pueden ser tanto desde una vertiente psicosocial en la salud mental (fatiga informática, carga mental ${ }^{10}$, estrés, etc.) del trabajador como desde una vertiente ergonómica, en forma de daños musculoesqueléticos (dolores de espalda y problemas en las articulaciones).

Como se ha asentado en la introducción, el derecho laboral aquí tratado permite que el trabajador pueda no estar conectado de la empresa y así poder conciliar y descansar. Un derecho destacable y que debe ser regulado con la máxima garantía a nivel de la Unión Europea por medio de una Directiva. En este sentido, la digitalización en el trabajo provoca dificultades para separar el descanso y la conciliación de los trabajadores. La vida profesional debe ir por un lado y la privada por otro, no se deben mezclar. El trabajador comunitario ha de priorizar la conciliación y, fuera de su jornada de trabajo desconectar sus dispositivos digitales dado que los riesgos psicosociales a los que se puede enfrentar por la falta de descanso y el uso excesivo de los dispositivos digitales pueden ser muy graves.

Conscientes de esta realidad, de conformidad con el artículo 225 del Tratado de Funcionamiento de la Unión Europea (TFUE ${ }^{11}$ ), el pasado 1 de diciembre de 2020 en una resolución adoptada con 31 votos a favor, 6 votos en contra y 18 abstenciones, los eurodiputados de la Comisión de Empleo afirmaron que los países de la Unión Europea (UE) debían garantizar que los trabajadores pudieran ejercer el derecho a desconectarse ("right to disconnect") de forma eficaz, incluso mediante convenios colectivos. Sostuvieron que este derecho es vital para proteger la salud de los trabajadores ${ }^{12}$. Máxime

\footnotetext{
9 Vid. Domingo Monforte, Jose y Salvador Álvarez, Neus, "Hiperconectividad digital y salud laboral", Diario La Ley, ISSN 1989-6913, nº 9638, 2020.

${ }^{10}$ Vid. Sebastián García Olga, y Del Hoyo Delgado, María Ángeles, La carga mental del trabajo, Instituto Nacional de Seguridad e Higiene en el Trabajo Composición e impresión: Servicio de Ediciones y Publicaciones. INSHT, 2016, Madrid ISBN: 84-7425-605-4, p. 16, recuperado de: https://www.insst.es/documents/94886/96076/carga+mental+de+trabajo/2fd91b55-f191-4779-be4f2c893c2ffe37 [Consulta a 2 junio 2020].

${ }^{11}$ Según el cual "por decisión de la mayoría de los miembros que lo componen, el Parlamento Europeo podrá solicitar a la Comisión que presente las propuestas oportunas sobre cualquier asunto que a juicio de aquél requiera la elaboración de un acto de la Unión para la aplicación de los Tratados. Si la Comisión no presenta propuesta alguna, comunicará las razones al Parlamento Europeo".

${ }^{12}$ Vid. European Parliament, DRAFT OPINION of the Committee on Employment and Social Affairs for the Committee on Industry, Research and Energy on a New Industrial Strategy for Europe (2020/2076(INI)) Rapporteur for opinion: Jordi Cañas, recuperado de: https://www.europarl.europa.eu/doceo/document/EMPL—PA—652607_EN.pdf [Consulta a 17 de junio 2020].
} 
cuando fuera de Francia, Bélgica, Italia o España, existen países europeos sin legislación propia sobre esta materia laboral. Los Países Bajos y Portugal, se han hecho propuestas legislativas pero el proceso se está estancando. Luego, en ocho países (Alemania, Finlandia, Irlanda, Luxemburgo, Lituania, Malta, Suecia y Eslovenia) se está produciendo un debate más o menos intenso sobre el derecho a la desconexión, siendo las discusiones más avanzadas en Alemania, Malta ${ }^{13}$ e Irlanda ${ }^{14}$; en algunos, el debate ha resurgido en el contexto de la pandemia.

En los trece estados miembros restantes de la Unión Europea no hay debate sobre legislación. Se percibe que la legislación existente es suficiente, el trabajo flexible basado en las TIC no está muy extendido, como en la mayoría de los países de Europa del Este, o se prefiere la negociación colectiva cuando se trata de mejorar el equilibrio entre el trabajo y la vida, como en los países escandinavos. Y reincidiendo en lo ya señalado, la Comisión de Empleo es de la opinión que fuera del horario laboral, los trabajadores europeos deben poder apagar los dispositivos digitales sin sufrir consecuencias. La cultura de estar siempre activos y la creciente expectativa de que los trabajadores deben estar disponibles en cualquier momento pueden afectar negativamente el equilibrio entre la vida laboral y personal, la salud física y mental y el bienestar. En la misma resolución, pidieron a la Comisión la proposición de una Directiva de la UE sobre el derecho a desconectarse, ya que este derecho no está consagrado explícitamente en la legislación de

\footnotetext{
${ }^{13}$ Malta pretende ser uno de los primeros Estados miembros de la UE en hacer cumplir legalmente el concepto del derecho a desconectarse, tal y como se propuso el 20 de noviembre en palabras del ministro de la Oficina del Primer Ministro, Carmelo Abela. Ministro maltés que se reunió con la dirección y los secretarios del Sindicato General de Trabajadores, para garantizar en un futuro próximo un marco legislativo sobre el trabajo a distancia. Ello a en línea con la idea de la UE de garantizar el derecho a la desconexión de los trabajadores.

${ }^{14}$ A comienzos de 2021, el Ministro irlandés de Empresa, Comercio y Empleo solicitó a la Comisión de Relaciones en el Lugar de Trabajo -Workplace Relations Commission (WRC)- el diseño de un Código de Prácticas sobre el derecho de un empleado a desconectarse del trabajo. El WRC inició el trámite de consulta pública (finalizó el 22 de enero de 2021) para la redacción del Código que establecerá una guía para los empleados y empleadores en vistas a adoptar las mejores prácticas y enfoques para la desvinculación de los empleados fuera del horario laboral normal. Existen empresas como AIB, que cuentan con protocolos. De hecho fue la primera empresa en Irlanda en acordar junto con el sindicato Financial Services Union una política "right to disconnect " para sus trabajadores. Conviene añadir que este Código de prácticas no es una ley en sentido estricto y por tanto no es vinculante. Aun así, de darse el efecto disuasorio dado que en caso de incumplir su contenido puede ser tratado como prueba en tribunales laborales irlandeses. Estos Códigos pueden incluir desde prácticas sobre el acceso al trabajo a tiempo parcial (que puede ser relevante en relación con las demandas por discriminación en el trabajo a tiempo parcial) hasta prácticas sobre procedimientos disciplinarios y de quejas. Quizás, el legislador irlandés ha utilizado esta vía no legislativa porque la legislación sobre el tiempo de trabajo (la Ley de organización del tiempo de trabajo de 1997 "OWTA") ya incluye normas específicas sobre el horario de trabajo, los períodos de descanso y las pausas de descanso. Podría decirse que estas normas legales ya implican el derecho a dejar de trabajar o desconectarse.
} 
la UE. Incluso, los mismos eurodiputados subrayaron la posibilidad de desconectar del trabajo ha de ser considerado como un derecho fundamental, que permita a los trabajadores abstenerse de tareas laborales y de comunicación electrónica fuera del horario laboral sin sufrir repercusiones. A fecha de 21 de enero de 2021, en el Parlamento se debatieron estos extremos y como resultado, se aprobó -472 votos a favor, 126 en contra y 83 abstenciones- un informe de iniciativa legislativa, por el cual, los eurodiputados proponen a la Comisión una ley para garantizar a los trabajadores el derecho a desconectarse fuera del horario laboral sin temor a repercusiones y considerar como un derecho fundamental el derecho de desconexión. También, en el mismo informe se reclaman unos requisitos mínimos para el trabajo a distancia y esclarecer las condiciones laborales y los horarios de trabajo y de descanso.

Reincidiendo en lo ya señalado, a nivel comunitario existe normativa sobre tiempo de trabajo (Directiva 2003/88/EC) que protege al trabajador para que pueda descansar tras su jornada laboral. Directiva que determina los siguientes extremos:

- Un límite a las horas de trabajo semanales. El tiempo medio de trabajo para cada período de siete días no debe superar las 48 horas, incluidas las horas extraordinarias; según la legislación nacional y/o los convenios colectivos, la media de 48 horas se calcula sobre un período de referencia de hasta 4, 6 o 12 meses.

- Un descanso durante las horas de trabajo si el trabajador está de servicio durante más de 6 horas.

- Un período mínimo de descanso diario. Cada 24 horas un trabajador tiene derecho a un mínimo de 11 horas consecutivas de descanso.

- Un período mínimo de descanso semanal por cada período de 7 días, un trabajador tiene derecho a un mínimo de 24 horas ininterrumpidas además de las 11 horas de descanso diario.

- Vacaciones anuales retribuidas de al menos 4 semanas al año.

Si bien la Directiva fija unos claros tiempos máximos de trabajo y mínimos de descanso, específicamente, la normativa comunitaria no cuenta con regulación propia y específica sobre desconexión digital en el trabajo. En este contexto, los eurodiputados apuestan por una regulación futura que concrete este derecho tan necesario para los trabajadores a nivel comunitario y que se encuentren protegidos, esto es, que las empresas no les exijan una conectividad aun estando en tiempos de descanso y de conciliación familiar. En caso de no ser así, la futura normativa comunitaria debe tutelar al trabajador para que no sea 
víctima y pueda invocar su derecho gracias a la existencia de mecanismos de tramitación de quejas y de un régimen sancionador concreto. Y no solo con una regulación profusa y concreta, los eurodiputados también abogan por considerar el desenganche tecnológico como un derecho fundamental de la Unión Europea.

He aquí donde el derecho a la desconexión informática ha de imponerse y evitar que se mezclen los tipos de horas. El tiempo libre y de ocio siempre ha de respetarse por lo que la desconexión digital en el trabajo cumple esta función esencial para el descanso del trabajador. El empresario ha de ser sabedor de ello y no extralimitarse en su poder de dirección y control; esto es, no impartir órdenes e instrucciones que afecten a los períodos de no trabajo. Ahora bien, según amplia jurisprudencia ${ }^{15}$ existe una presunción de legitimidad en las órdenes del empresario, salvo eso sí, vulnere derechos fundamentales, lo cual, como se analizará, si se concreta la iniciativa legislativa y se reconoce el derecho a la desconexión como fundamental, directamente, el empleador deberá justificar de forma objetiva y concretar con la representación legal de los trabajadores los casos en los que los trabajadores tendrán que obedecer las órdenes recibidas por sus superiores fuera de su jornada laboral pactada. No en vano existen convenios colectivos y protocolos internos que inaplican el derecho ante circunstancias excepcionales que necesitan ser atendidas, de urgencia, por los trabajadores. Lo determinan de forma general, como un cajón de sastre y sin mayores concreciones; ello puede suponer un perjuicio grave para el trabajador ante usos abusivos de esta razón para que el trabajador esté siempre conectado. Se exige por parte de las empresas detallar con mayor claridad estas circunstancias urgentes para que no sea una generalidad, sino una excepción.

\section{Estudio de la iniciativa legislativa}

Asentado el contexto anterior, en este punto, merece especial atención desgranar el contenido $^{16}$ de la iniciativa legislativa comunitaria para reflexionar y determinar aquello que puede acarrear para los países comunitarios pues, en caso de salir adelante, deberán amoldar su ordenamiento jurídico interno a dicho contenido. En esta tarea se pondrá el contenido comunitario en reflejo a la normativa española a efectos de comparación.

\footnotetext{
${ }^{15}$ Entre otras muchas sentencias, vid. sentencias del TSJ de Castilla y León (Valladolid) de 2 de octubre de 1998, Ar./4484; de Extremadura de 9 de febrero de 1998, Ar./5152; de Madrid de 18 de diciembre de 1997, Ar./4589; de Andalucía (Málaga) de 11 de abril de 1997, Ar./1619; de Cataluña de 5 de noviembre de 1996, Ar./4091; Baleares de 17 de julio de 1996, Ar./3165; de Canarias (Santa Cruz de Tenerife) de 28 de octubre de 1994, Ar./3987; de Andalucía (Sevilla) de 21 de febrero de 1992, Ar./1096, o la de Andalucía (Granada) 27 de abril de 1992, Ar./2197.

${ }^{16} \mathrm{El}$ texto acompañado de un anexo y que fue adoptado con fecha de 21 de enero de 2021 en Bruselas, se encuentra disponible (en inglés) a través de la web del Parlamento Europeo (2021). Recuperado de: https://www.europarl.europa.eu/doceo/document/TA-9-2021-0021_EN.html\#title2 [Consulta a 8 de marzo de 2021].
} 
Normativa nacional que, como es sabido, descansa en la LOPDPGDD (ex. artículo 88) y en el RDLTD (ex. artículo 18).

Particularmente, el anexo a la resolución del Parlamento Europeo para la futura Directiva está compuesto por 14 artículos. Comienza analizando el objeto y el alcance, dejando claro que la Directiva pretende detallar los requisitos mínimos para permitir que los trabajadores comunitarios que utilicen herramientas digitales con fines laborales, puedan ejercer su derecho a desconectarse. También pretende "garantizar" es decir, no obligar a que los empresarios respeten el presente derecho. Al igual que sucede en España y Francia, y de forma atinada, la Directiva va dirigida tanto a empresas públicas como privadas y con independencia de la modalidad contractual que tengan, sobre todo en las empresas privadas, los trabajadores (artículo 1). En consecuencia, los trabajadores temporales, por ejemplo, provenientes de Empresas de Trabajo Temporal, también han de tener la misma garantía de ejecutar su derecho a desconectarse digitalmente de la empresa (usuaria) al término de su jornada laboral pactada. A continuación, define "desconectar" como el hecho de "no participar en actividades relacionadas con el trabajo o comunicaciones por medio de herramientas digitales, directa o indirectamente, fuera del horario laboral" (artículo 2). Esta definición ya es reseñable, habida cuenta que la normativa española no define en sí el término de desconexión digital.

Seguidamente, se encomienda a los Estados miembros 1) "a que garanticen que los empresarios adopten las medidas necesarias para proporcionar a los trabajadores los medios para ejercer su derecho a desconectar". En España, en cumplimiento de la normativa se les obliga a redactar políticas internas sobre las modalidades del derecho, así como se les insta a que sea en la negociación colectiva -previa audiencia con los representantes legales de los trabajadores- el medio en el que se establezcan las actuaciones sobre desconexión digital. Con el precepto de la propuesta Directiva, quizás España debería garantizar de mejor forma esta obligación empresarial con un régimen sancionador más severo y con más obligaciones que las genéricas relativas a la redacción de códigos internos y a convenios colectivos con cláusulas sobre desconexión digital. Y, además, que 2) "los Estados miembros garantizarán que los empresarios establezcan un sistema objetivo, fiable y accesible que permita medir la duración del tiempo trabajado cada día por cada trabajador, de conformidad con el derecho de los trabajadores a la intimidad ya la protección de sus datos personales. Los trabajadores tendrán la posibilidad de solicitar y obtener el registro de sus horas de trabajo" (artículo 3). En principio, en España, se cumple de conformidad con el Real Decreto-ley 8/2019 por el que se obliga a las empresas a disponer de un registro diario de jornada, que deberá incluir el horario concreto de inicio y finalización de la jornada de trabajo de cada persona trabajadora. Sin embargo, este registro suele ser en los centros de trabajo físicos con el sistema de fichaje, la normativa actual debería tener en cuenta los centros de trabajo 
analógicos y computar el registro de jornada de trabajo llevada a cabo por medios digitales para que así, no se sobrepase el trabajador en su jornada por contestar mensajes o llamadas telefónicas en tiempos de descanso. Finalmente, el precepto determina que los Estados miembros deberán velar que los "empleadores apliquen el derecho a desconectarse de manera justa, legal y transparente”. Los empresarios han de adoptar medidas de desconexión digital sin discriminación, atendiendo por igual a los trabajadores y trabajadores (es muy importante la perspectiva de género), a las cargas familiares, a los trabajadores con minusvalía, trabajadores temporales, trabajadores a tiempo parcial, etc.

A propósito del registro de la jornada laboral de cuyo incumplimiento está considerada como una infracción grave, es de significar su directa vinculación con el ejercicio del derecho a la desconexión digital ${ }^{17}$ pues supone una barrera a la realización de horas extraordinarias (reguladas ex artículo $35 \mathrm{ET}$, siendo su número como máximo de 80 horas anuales) sin retribución y, desde luego, a la falta de descanso e intimidad tras la jornada laboral. Para conseguir que el binomio registro de la jornada y desconexión digital sean inseparables, es necesario contar con sistemas que computen las horas eficazmente ${ }^{18}$. Este registro de jornada obligatorio en España está regulado por medio del Real Decreto-ley $8 / 2019$, de 8 de marzo, de medidas urgentes de protección social y de lucha contra la precariedad laboral en la jornada de trabajo (BOE 12 marzo). Esta regulación supuso un paso importante para dar respuesta a estas cuestiones y también al mandato constitucional del artículo 40.2 CE, fue la publicación del Real Decreto-ley 8/2019, de 8 de marzo, de medidas urgentes de protección social y de lucha contra la precariedad laboral en la jornada de trabajo, que, con efectos del 12 de mayo de 2019, modifica el artículo 34 ET, instaurando el deber de la empresa de garantizar el registro diario de jornada, que deberá incluir el horario concreto de inicio y finalización de la jornada de trabajo de cada persona trabajadora, sin perjuicio de la flexibilidad horaria existente. Con este registro, se obliga a las empresas a tener un control efectivo del número de horas reales que trabajan sus empleados.

En términos jurisprudenciales, es de destacar la reciente sentencia del Juzgado de lo Social 3 de Palma de Mallorca por la que se admite el registro horario que ofrecen las conexiones de los ordenadores ${ }^{19}$. Más en concreto, se condena a la empresa por exceso

\footnotetext{
${ }^{17}$ Vid. SerRano Olivares, Raquel y Sabaté CANelles, Mireia, "Los derechos a la desconexión digital y al registro de la jornada”, Revista jurídica de Catalunya, ISSN 1575-0078, vol. 118, 2019.

${ }^{18}$ Vid. ARRIETA IDIAKEZ, Francisco Javier, "La desconexión digital y el registro de la jornada diaria en España como mecanismos para garantizar el descanso, la salud y el bienestar de los trabajadores digitales a distancia", Lan harremanak: Revista de Relaciones Laborales, 2019, p. 42.

${ }^{19}$ Vid. Netrisk, Registro horario: estar conectado al ordenador se considera tiempo trabajado. Entrad en Netrisk, recuperado de: https://netriskprevencion.com/Registro-horario-estar-conectado-al-ordenador-seconsidera-tiempo-trabajado-14 [Consulta a 14 julio de 2020].
} 
de jornada, habiendo cometido dos infracciones graves (en grado máximo). El fallo, de marzo de 2020, se refiere a un caso anterior a la entrada en vigor del señalado registro de jornada, pero introduce una novedad aplicable a la nueva normativa del control de jornada: la jueza admite el registro que ofrecen las conexiones de los ordenadores de los empleados, con lo que la mera constancia de que el dispositivo ha estado encendido un número de horas presume que todo ese tiempo constituye jornada de trabajo. En este caso, se trató de las conexiones realizadas a dos programas que, a juicio de la jueza, demuestran el exceso de jornada.

Para hacer efectivo el derecho a la desconexión digital, este registro que, según lo señalado cubre las conexiones realizadas por los trabajadores, ha de ser fehaciente y real, esto es: los datos almacenados deben corresponderse con las horas trabajadas y debe registrar la hora de entrada y la hora de salida ${ }^{20}$. Esta nueva obligación en el registro horario no está exenta de debate pues, es un asunto delicado sobre todo, como se ha señalado en líneas anteriores, desde empresas que cuentan con trabajos flexibles, por ejemplo, por proyectos en los que precisamente se trabaja sin límite horario así como, para los teletrabajadores o desplazados en los que resulta muy difícil controlar su jornada laboral y, en consecuencia, la prolongación de la jornada puede ir en contra del cobro de las horas extraordinarias. Estadísticamente, según datos del primer trimestre del 2020 extraídos del Instituto Nacional de Estadística ${ }^{21}$, el total de horas extras no pagadas para todos los asalariados fue de 3.130,1 miles/horas (hombres $1.747,7$ y mujeres $1.382,4$ ). En efecto, la modalidad de teletrabajo disparó durante el confinamiento el fraude laboral y tributario de las horas extraordinarias no pagadas. Según datos de la última Encuesta de Población Activa (EPA) en el segundo trimestre del mismo año - que discurrió entre la fase más dura del confinamiento y el regreso a la llamada nueva normalidad-, los asalariados españoles llegaron a trabajar gratis 3.798 .700 horas semanales $(49,38$ millones de abril a junio) de más, sin recibir a cambio ninguna remuneración.

Tanto es así que, durante la crisis sanitaria, la Inspección de Trabajo y de la Seguridad Social (ITSS) ha sancionado a cerca de 2.000 empresas por incumplir la jornada laboral. Con unas multas que oscilan entre los 626 y los 6.250 euros $^{22}$. En concreto, Según datos

\footnotetext{
${ }^{20}$ Existen soluciones tecnológicas que permiten generar un registro de cuando el trabajador comienza a trabajar y cuando acaba, dado que se dispone de la información de cuando se han conectado los dispositivos corporativos a la red inalámbrica corporativa y cuando se han desconectado. A este propósito: las aplicaciones Control horario o Cucorentde (ambas disponibles en Google Play) no solo registran la jornada laboral, también reflejan las tareas concretas en las que se está trabajando.

${ }^{21}$ Vid. Instituto Nacional de Estadística (INE), Número total de horas extraordinarias realizadas en la semana por todos los asalariados por sexo y ocupación 2020-T2, recuperado de: https://www.ine.es/jaxiT3/Datos.htm?t=4366\#!tabs-tabla [Consulta a 2 de junio 2020].

${ }^{22}$ Vid. ESCRICHE RIVAS, Elisabet, "L'Estat sanciona 2.000 empreses per incomplir la jornada laboral". Ara.cat, recuperado de: https://m-ara-cat.cdn.ampproject.org/c/s/m.ara.cat/economia/estat-sanciona-2000-
} 
del Ministerio de Trabajo, de principios de marzo hasta finales de septiembre la ITSS sancionó a 1.916 empresas por incumplimientos relacionados con las jornadas laborales. Multas provocadas por empresas que no han pagado horas extras ni han compensado con tiempo de descanso, otras que han incumplido el máximo de 80 horas extraordinarias que un trabajador puede hacer al año o, como es al interés, empresas que han vulnerado el derecho a la desconexión digital. El total de sanciones emitidas por Trabajo ascendió en dichos meses a más de 2.306.000 de euros. Desde luego, la desconexión digital durante el confinamiento y la crisis sanitaria ha provocado este aumento de sanciones porque los trabajadores a distancia no pueden estar conectados cada día de la semana a todas horas. En este terreno, el derecho a la desconexión digital y el registro obligatorio de la jornada son un binomio que ha de ser tratado en su conjunto en la empresa, por ejemplo, en la elaboración de una política interna.

Descendiendo en el anexo, el artículo 4 cuenta con un contenido amplio (compuesto por tres apartados ${ }^{23}$ ) dedicado a un aspecto esencial para la garantía del derecho: las medidas

empreses-incomplir-jornada-laboral-crisi-sanitaria-coronavirus-COVID-19_0_2544345563.amp.html [Consulta a 14 de octubre 2020].

${ }^{23}$ Dada su relevancia se recoge, seguidamente su contenido de forma literal:

“1. Los Estados miembros velarán para que se establezcan disposiciones detalladas, previa consulta a los interlocutores sociales al nivel apropiado, para permitir que los trabajadores ejerzan su derecho a desconectarse y que los empresarios apliquen ese derecho de manera justa y transparente. A tal fin, los Estados miembros establecerán al menos las siguientes condiciones laborales:

a) las modalidades prácticas para apagar las herramientas digitales con fines laborales, incluidas las herramientas de seguimiento relacionadas con el trabajo;

(b) el sistema de medición del tiempo de trabajo;

(c) evaluaciones de salud y seguridad, incluidas evaluaciones de riesgo psicosocial, con respecto al derecho a desconectarse;

(d) los criterios para determinar cualquier excepción por parte de los empleadores de su requisito de implementar el derecho del trabajador a desconectarse;

e) en el caso de una excepción en virtud de la letra d), los criterios para determinar cómo se calculará la compensación por el trabajo realizado fuera del horario de trabajo de conformidad con las Directivas 89/391 / CEE, 2003/88 / CE (UE) 2019/1152 y (UE) 2019/1158, y con las leyes y prácticas nacionales.

f) las medidas de sensibilización, incluida la formación en el lugar de trabajo, que deben adoptar los empleadores con respecto a las condiciones laborales a que se refiere el presente párrafo.

Cualquier excepción en virtud del párrafo primero, letra d), se establecerá únicamente en circunstancias excepcionales, como fuerza mayor u otras emergencias, y estará sujeta a que el empleador proporcione a cada trabajador interesado las razones por escrito, justificando la necesidad de la excepción en cada caso. ocasión en la que se invoca la excepción

2. Los Estados miembros podrán, de conformidad con la legislación y la práctica nacionales, encomendar a los interlocutores sociales la celebración de convenios colectivos a nivel nacional, regional, sectorial o empresarial que establezcan o complementen las condiciones de trabajo mencionadas en el apartado 1.

3. Los Estados miembros garantizarán que los trabajadores que no estén cubiertos por un convenio colectivo de conformidad con el apartado 2 se beneficien de la protección de conformidad con la presente Directiva". 
a implementar. De una forma más completa que en la normativa española, se determinan medidas muy concretas, como el apagado de las herramientas, las mediciones del tiempo de trabajo, la formación y la sensibilidad en el uso razonable de las TIC, y la exactitud en las situaciones en los que los empresarios podrán invalidar el derecho a la desconexión digital en el trabajo. Y no solo ello, según el texto de la iniciativa comunitaria, todo ello ha de ser consensuado con los representantes legales de los trabajadores. Igualmente, en conjunción con la representación, se han de establecer los criterios para determinar la compensación del trabajador que no pueda descansar de la tecnología por tener que actuar en situaciones de urgencia y de emergencia empresarial. Obviamente esta retribución económica (extraordinaria) será al menos de igual cuantía de las retribuciones (ordinarias) que disfruta el trabajador según lo pactado en condiciones normales.

En efecto, poniendo de relieve este importante precepto con los artículos 88 y 18 de la LOPDPGDD y del RDLTD, respectivamente, se observa una mayor profundidad en la adopción de medidas de implementación del derecho. De adoptarse este contenido a la normativa vigente española, se virtualizaría más el derecho y se generarían más condicionantes para que la empresa, como obligada y previa consulta con la representación de trabajadores, determine las modalidades prácticas del derecho. Resulta digno de destacar el apartado c) dado que la desconexión digital si bien es una cuestión laboral con muchas aristas y que debe ser pulido, la arista relativa a la seguridad y salud es la más evidente. España debería amoldar su contenido normativo a esta prescripción bien en la Ley 31/1995, de 8 de noviembre, de prevención de Riesgos Laborales (LPRL) bien en un reglamento de desarrollo (o específico o añadiendo contenido a otro ya existente como el importante Real Decreto 39/1997, de 17 de enero, por el que se aprueba el Reglamento de los Servicios de Prevención -RSP-). Sea cual sea en que se vehiculice este desarrollo, la empresa, como garante de la seguridad y salud de sus trabajadores ha de velar por el bienestar, poniendo acento en su planificación de la actividad preventiva en los riesgos psicosociales y en los riesgos ergonómicos propios de la falta de descanso tecnológico.

Aunque caben excepciones que invalidan el derecho, por ejemplo, frente a circunstancias de grave perjuicio para la empresa que exija una inmediatez de respuesta (casos de fuerza mayor como muchos convenios colectivos y políticas internas determinan en España). Siguiendo el texto de borrador de Directiva, lo cierto es que habría que ir al caso particular para que el derecho no se ejerza, pero ha de recalcarse que los trabajadores quedarían más protegidos si sus empresas contasen en su convenio colectivo de aplicación con una política interna detallada sobre desconexión digital con medidas y herramientas que permitan garantizar la preservación del derecho y conseguir un descanso necesario para el bienestar de los trabajadores. Sea cual sea la forma, el empleador como sigue el precepto de borrador de Directiva el empleador “(...) ha de proporcionar razones por 
escrito, justificando la necesidad de la excepción en cada caso. ocasión en la que se invoca la excepción".

Como se aprecia, el derecho laboral no es absoluto dado que puede quedar invalidado esto es, se puede contactar a los trabajadores aun en periodos de descanso- ante supuestos excepcionales y con carácter de urgente necesidad. En España, la Disposición Adicional $1^{\text {a }}$ del RDLTD (apdo. 2) por el que "los convenios o acuerdos colectivos podrán regular (...) las posibles circunstancias extraordinarias de modulación del derecho a la desconexión digital'. En consecuencia, el legislador está dejando entrever las posibles circunstancias excepcionales que pueden motivar que los empleados fuera de su horario de trabajo deban estar pendiente de llamadas o mensajes al teléfono móvil o al correo electrónico. En estos casos, la empresa en vista a un posible perjuicio que pueda sufrir puede contactar a sus empleados mediante una llamada o mensaje corto para que se pueda resolver con inmediatez dicha urgencia excepcional. Los protocolos de actuación interna, así como los convenios colectivos determinan en muchas ocasiones está excepción del derecho laboral pero no deja de ser una generalidad sin mayores concreciones (¿qué tipos de supuestos son?). Aparte de que deberían detallar estos supuestos de imperiosa necesidad como puede ser por medio de ejemplos, también podrían suscribir, si es necesario, un acuerdo fijando una hora u horquilla horaria para que los trabajadores sepan que deben revisar sus dispositivos digitales (móvil, ordenador, etc.).

Continuando en el análisis del texto de la iniciativa, en lo atinente al régimen sancionador (artículo $5^{24}$ ), cabe recalcar que de no existir un protocolo de actuación frente al derecho,

\footnotetext{
${ }^{24}$ Rubricado como "Protección contra el tratamiento adverso" y que reza de la siguiente forma:

"1. Los Estados miembros velarán por que se prohíba la discriminación, el trato menos favorable, el despido y otras medidas adversas por parte de los empresarios por haber ejercido o tratado de ejercer su derecho de desconexión por parte de los trabajadores.

2. Los Estados miembros velarán por que los empleadores protejan a los trabajadores, incluidos los representantes de los trabajadores, de cualquier trato adverso y de cualquier consecuencia adversa que resulte de una queja presentada al empleador o de cualquier procedimiento iniciado con el objetivo de hacer cumplir los derechos previstos. en esta Directiva.

3. Los Estados miembros velarán para que cuando los trabajadores que se consideren despedidos o sometidos a un trato desfavorable por haber ejercido o intentado ejercer su derecho de desconexión establezcan ante un tribunal u otra autoridad competente los hechos que consideren que puedan dar lugar. Si se presume que han sido despedidos o sometidos a otro trato adverso por tales motivos, corresponderá al empleador demostrar que el despido u otro trato adverso se basó en otros motivos.

4. El apartado 3 no impedirá que los Estados miembros introduzcan normas probatorias más favorables para los trabajadores.

5. Los Estados miembros no estarán obligados a aplicar el apartado 3 a los procedimientos en los que corresponda al tribunal u organismo competente investigar los hechos del caso.

6. El apartado 3 no se aplicará a los procedimientos penales, a menos que los Estados miembros dispongan lo contrario".
} 
la empresa no puede sancionar a ningún trabajador por ejercer su derecho a desconexión digital ni, tampoco, verse perjudicado en su desarrollo profesional; por lógica, dado que no está obligado a responder llamadas o mensajes fuera de su horario laboral, un despido por esta circunstancia, a todas luces sería improcedente (siempre ponderando la gravedad, por lo que será el juez quien lo determine; no es lo mismo no responder a un mensaje puntual como no responder a múltiples mensajes, o directamente, nunca). Sin desdeñar la posibilidad de que el despido pueda ser calificado como nulo (con la readmisión del trabajador que haya denunciado y sido despedido por este motivo) dado que la Directiva considera que se trata de un derecho fundamental del trabajador.

Al ser un derecho a favor del trabajador correlativamente, supone una obligación por la empresa; el incumplimiento empresarial, según el artículo 5 del texto es denunciable ante los juzgados y autoridades laborales. Las autoridades laborales de los países comunitarios (como en España es la ITSS ${ }^{25}$ ) acogerán de buen recibo todas aquellas pruebas que los trabajadores puedan recabar ante supuestos de transgresión de su derecho a la desconexión digital. Por ejemplo, pueden servir pruebas en forma de impresiones de correos electrónicos ${ }^{26}$ o capturas de mensajes vía programas de mensajería instantánea (por ejemplo, WhatsApp ${ }^{27}$ ). De una forma u otra se puede demostrar la fecha y hora de la recepción del mismo. Con estos medios de prueba, las autoridades comunitarias y los juzgados tendrán más posibilidades de controlar y vigilar el cumplimiento de la Directiva.

En virtud del precepto $6^{28}$ (derecho de reparación) se aboga por la celeridad en las resoluciones de conflictos sobre esta materia y además que sean efectivas e imparciales.

\footnotetext{
${ }^{25}$ En efecto, en España, los trabajadores pueden interponer una demanda a su empresa o bien, denunciar efectivamente, ante la ITSS (incluso de forma anónima y gratuita por medio de su portal web: Buzón de lucha contra el fraude). Los inspectores encuentran difícil controlar y vigilar este derecho digital por sus particularidades -aparte del smartphone, hay empresas que utilizan herramientas internas que dificultan su comprobación y conocimientos sobre el modo en que se utilizan- por lo que toda prueba objetiva es bienvenida, como se afirmaba; ya sea un pantallazo del WhatsApp como a través de la Intranet de la empresa o aplicaciones tipo $V P N$.

${ }^{26}$ A este propósito, según la sentencia del Tribunal Supremo (Sala de lo Social) 706/2020 (rec. 239/2018), de 23 de julio de 2020, el correo electrónico puede aportarse como prueba documental en el juicio laboral. ${ }^{27}$ Aunque habrá que ir al caso porque existe jurisprudencia española (STSJ de Galicia, Sala de lo Social, de 26 de marzo de 2019, rec. núm. 440/2019) que determina que un WhatsApp no se considera como prueba documental para revisar los hechos y poder recurrir en suplicación conforme al artículo 193 b) de la Ley 36/2011, de 10 de octubre, reguladora de la jurisdicción social (en lo sucesivo, LJS. BOE 11/10/2011).

${ }^{28}$ 1. Los Estados miembros garantizarán que los trabajadores cuyo derecho a desconectarse sea violado tengan acceso a una resolución de litigios rápida, efectiva e imparcial y un derecho de reparación en caso de vulneración de sus derechos derivados de la presente Directiva.

2. Los Estados miembros podrán ofrecer a las organizaciones sindicales u otros representantes de los trabajadores la posibilidad, en nombre o en apoyo de los trabajadores y con su aprobación, de entablar procedimientos administrativos con el objetivo de garantizar el cumplimiento o la aplicación de la presente Directiva".
} 
Obviamente en estos conflictos se sustentará por el agraviado su derecho de reparación por la vulneración de un derecho que, tendrá de materializarse. cabida en la Directiva aquí analizada. Y estos procesos de demandas que han de ser preferentes y sumarios casan con aquellos derechos que tienen la consideración de fundamental. Y la Directiva considera que el derecho a la desconexión digital resulta una cuestión fundamental para los trabajadores por ser atentatoria a "las condiciones de trabajo justo, incluida una remuneración justa, la limitación del tiempo de trabajo y el equilibrio entre la vida personal y laboral, la salud y la seguridad física y mental en el trabajo y el bienestar, así como, debido a su impacto desproporcionado en los trabajadores con responsabilidades de cuidado, que tienden a ser mujeres, igualdad entre hombres y mujeres". En consecuencia, de considerarse como derecho fundamental, en España, cabe recordar que la protección jurisdiccional de los derechos fundamentales y libertades públicas ante los Tribunales ordinarios se instrumenta para cualquier ciudadano, de igual forma que determina el borrador de la Directiva, a través de un procedimiento especial, preferente y sumario (ex. artículo 53.2 de la Constitución Española -CE-). Adicionalmente, resulta reseñable la posibilidad, tal y como determina la $\mathrm{CE}$ de proteger los derechos fundamentales por medio del Recurso de Amparo constitucional.

Un derecho fundamental vincula a todos los poderes públicos y se deberá regular por ley, más particularmente, por ley orgánica, dado que según preceptúa el artículo 81 de la Carta Magna, se regulan por este tipo de ley, entre otras materias, el desarrollo de derechos fundamentales.

No menos importante resulta el artículo $7^{29}$ del texto de la iniciativa legislativa. Un precepto referido a la obligación del empresario de comunicar a todo el personal cuál es

\footnotetext{
29 “Obligación de facilitar información:

Los Estados miembros velarán por que los empresarios proporcionen a cada trabajador por escrito información clara, suficiente y adecuada sobre su derecho a desconectarse, incluida una declaración en la que se establezcan las condiciones de los convenios colectivos u otros convenios aplicables. Dicha información incluirá al menos lo siguiente:

a) las modalidades prácticas para apagar las herramientas digitales con fines laborales, incluidas las herramientas de seguimiento relacionadas con el trabajo, a que se refiere el artículo 4, apartado 1, letra a);

b) el sistema de medición del tiempo de trabajo a que se refiere el artículo 4, apartado 1, letra b);

c) las evaluaciones de salud y seguridad del empleador con respecto al derecho a desconectarse, incluidas las evaluaciones de riesgo psicosocial, a que se refiere el artículo 4, apartado 1, letra c);

d) los criterios para cualquier excepción al requisito de los empleadores de aplicar el derecho de desconexión y cualquier criterio para determinar la compensación por el trabajo realizado fuera del horario de trabajo, según se indica en el artículo 4, apartado 1, letras d) ye);

e) las medidas de sensibilización del empleador, incluida la formación en el trabajo, a que se refiere el artículo 4, apartado 1, letra f);

f) las medidas para proteger a los trabajadores contra el trato adverso de conformidad con el artículo 5;
} 
su política sobre el derecho a desconectarse ${ }^{30}$. Cuanta mayor información mejor por lo que todos estos apartados deben ser comunicados en el escrito individual a todo trabajador con independencia de su vinculación laboral con la empresa. Hay muchas fórmulas, desde subir un documento a la Intranet a otorgar una copia física de la política a todo trabajador.

De conformidad con el artículo $8^{31}$ (sanciones) los países comunitarios deberán adoptar todas las medidas necesarias para garantizar el cumplimiento del derecho. En caso de incumplimientos, las sanciones han de ser efectivas, proporcionadas y disuasorias. En este sentido, el texto de la Directiva al igual que sucede en la normativa española no menciona explícitamente el tipo de infracción -quizás por configurarse como un derecho del trabajador y no como un deber empresarial-, no obstante, ello no significa que el aparato sancionador de cada país actúe; existen, así en España, otros preceptos según los cuales se pueden imponer sanciones económicas o incluso penas de prisión ${ }^{32}$ a los incumplidores. En este terreno, ha de delimitarse el bien jurídico que protege el legislador por medio del derecho a la desconexión digital que nace en la normativa de protección de datos, para con ello, determinar los mecanismos de tutela aplicables. Lo cierto es que son

g) las medidas para aplicar el derecho de reparación de los trabajadores de conformidad con el artículo 6".

${ }^{30}$ Vid. TruJILlo PONS, Francisco, "La importancia de la comunicación interna en PRL", Gestión práctica de riesgos laborales: Integración y desarrollo de la gestión de la prevención, 2019, p. 166.

31 “Los Estados miembros establecerán las normas sobre las sanciones aplicables a las infracciones de las disposiciones nacionales adoptadas de conformidad con la presente Directiva, o de las disposiciones pertinentes ya en vigor relativas a los derechos que están dentro del ámbito de aplicación de la presente Directiva, y tomarán todas las medidas necesarias para garantizar que están implementados. Las sanciones previstas serán efectivas, proporcionadas y disuasorias. Los Estados miembros, a más tardar ... [dos años después de la fecha de entrada en vigor de la presente Directiva], notificarán a la Comisión dichas normas y medidas y le notificarán, sin demora, cualquier modificación posterior que les afecte".

${ }^{32} \mathrm{Y}$ ello porque las conductas anti-desconexión digital pueden ser consideradas como de acoso y de invasión a la privacidad [Vid. ReCHE Tello, Nuria, "La Desconexión digital como límite frente a la invasión de la privacidad" IUSLabor. Revista d'anàlisi de Dret del Treball, [en línea], n. ' 3, 2019, p. 3154, https://www.raco.cat/index.php/IUSLabor/article/view/362118 [Consulta: 4-6-2020]]. Los correos electrónicos indiscriminados, las videoconferencias, los mensajes de texto y las notas de voz pueden esconder conductas hostigadoras. En consecuencia, de acuerdo con el Código Penal se pueden imponer pena de prisión o de multa por delitos de acoso (artículo $173 \mathrm{CP}$ ). Bajo estas circunstancias aparee una modalidad de acoso, conocida como ciberacoso o "network mobbing" que, ciertamente, de materializarse puede ser probado con mayor facilidad que el que puede darse en los centros de trabajo físicos por la posibilidad que otorgan las TIC de guardar documentos, capturas e incluso imprimir correos electrónicos. En estos casos, el trabajador hostigado tiene protección desde varios prismas: 1) solicitando la rescisión del contrato por voluntad propia debido a graves incumplimientos contractuales del empresario (lo que implicaría la misma indemnización que por despido improcedente y la situación legal de desempleo); 2) solicitando una indemnización de daños morales o psíquicos y; 3) utilizando el procedimiento por violación de los derechos fundamentales (ex. artículo 181 LJS). 
muchos $^{33}$ pero, en suma, todos ellos (por un lado, derechos constitucionales como el descanso, la seguridad y salud y la protección de datos y, por otro lado, como el derecho a la conciliación familiar y laboral), permiten exigir una $u$ otra responsabilidad ${ }^{34}$-sobre todo, desde una vertiente administrativa merced al Real Decreto Legislativo 5/2000, de 4 de agosto, por el que se aprueba el texto refundido de la Ley sobre Infracciones y Sanciones en el Orden Social (en lo sucesivo, LISOS. BOE 8 agosto) ${ }^{35}$.

Conocer la normativa supone entender qué actuaciones de la empresa deben cesar, las posibles sanciones por incumplimientos, el papel de la ITSS en el control y la vigilancia del cumplimiento (que resulta muy complicado), así como el de la representación unitaria y sindical. Tanto es así que la ITSS ya está comenzando a proponer sanciones a empresas por enviar comunicaciones por medios electrónicos a los trabajadores fuera de la jornada laboral. Sanciones que pueden suponer un incumplimiento del derecho la desconexión digital sancionado con multas económicas de hasta 6.250 euros, salvo que se acredite que se dejó claro que la comunicación debe responderse en horario de trabajo.

Así con todo, dichas responsabilidades vienen reguladas, respectivamente, en la 1) LISOS donde primero según su artículo $7.5^{36}$ el incumplimiento de la obligación del registro de

33 Como recoge la doctrina: "si consideramos que tutela el derecho a descanso, las instituciones reguladoras del tiempo de trabajo serán las que deban establecer los límites. Si se considera que el bien protegido es la seguridad y salud de los trabajadores, obliga a una relectura de las obligaciones impuestas por la Ley de Prevención de Riesgos Laborales (en adelante, LPRL), especialmente significativa habida cuenta de la falta de desarrollo reglamentario en materia de riesgos psicosociales. Por su parte, desde el ámbito de la conciliación de la vida laboral y familiar, se abren nuevas oportunidades de regulación en el seno de los planes de igualdad. De considerarse protegido un derecho fundamental pueden activarse los mecanismos de tutela contra la vulneración de los mismos" Vid. ALTÉS TÁRREGA, Juan Antonio, y YAGÜE BLANCO, Sergio, “A vueltas con la desconexión digital eficacia y garantías de lege lata”, Labos: Revista de Derecho del Trabajo y Protección Social, 1(2), 2020, p. 61-87.

${ }^{34}$ Desde el plano de la seguridad y salud en el trabajo que tiene tanta vinculación con el derecho a la desconexión, conforme a la obra magna preventiva en España (LPRL), se reincide en esta cuestión en su artículo 42.1 del siguiente tenor literal: "el incumplimiento por los empresarios de sus obligaciones en materia de prevención de riesgos laborales dará lugar a responsabilidades administrativas, así como en su caso, a responsabilidades penales y a las civiles por los daños y perjuicios que puedan derivarse de dicho incumplimiento".

${ }^{35}$ Vid. en profundidad: TrujILlo PONS, Francisco, y TOSCANI GIMÉNEZ, Daniel, La desconexión digital en el trabajo, Aranzadi Thomson Reuters y Universidad de Valencia, 2020.

36 “La transgresión de las normas y los límites legales o pactados en materia de jornada, trabajo nocturno, horas extraordinarias, horas complementarias, descansos, vacaciones, permisos, registro de jornada y, en general, el tiempo de trabajo". Esta infracción -sin perjuicio de otras que pueda determinarse en cada caso, conlleva una sanción en su grado mínimo, de 626 a 1.250 euros, en su grado medio de 1.251 a 3.125 euros; y en su grado máximo de 3.126 a 6.250 euros (artículo 40 LISOS), pudiendo graduarse en función de las circunstancias agravantes previstas en el artículo 39 de la misma Ley. Es decir: “ a) La peligrosidad de las actividades desarrolladas en la empresa o centro de trabajo. b) El carácter permanente o transitorio de los riesgos inherentes a dichas actividades. c) La gravedad de los daños producidos o que hubieran podido 
la jornada está considerada como una infracción grave en materia de relaciones laborales y, segundo según su sección 2 (artículos 11 a 13) donde recoge el conjunto de infracciones en materia de prevención de riesgos laborales diferenciándolas en leves, graves y muy graves; 2) por extensión de la prevención de riesgos, en términos de recargo de prestaciones de la Seguridad Social ${ }^{37}$ en casos de accidentes de trabajo y enfermedades profesionales conforme al artículo 64 del Real Decreto Legislativo 8/2015, de 30 de octubre, por el que se aprueba el texto refundido de la Ley General de la Seguridad Social (en adelante LGSS. BOE 31 oct. 2015); 3) en caso de delitos, en el Código Penal (Ley Orgánica 10/1995, de 23 de noviembre, BOE 24 nov.) en cuyo artículo 316 se castiga a los que, con infracción de las normas de prevención de riesgos laborales y estando legalmente obligados, no faciliten los medios necesarios para que los trabajadores desempeñen su actividad con las medidas de seguridad e higiene adecuadas, de forma que pongan así en peligro grave su vida, salud o integridad física, con las penas de prisión de seis meses a tres años y multa de seis a doce meses y; 3 ) en el Código Civil (Real Decreto de 24 de julio de 1889, texto de la edición del Código Civil. Gaceta 25 julio 1889).

Por consiguiente, en casos de comunicaciones fuera del horario de trabajo se vulnera el derecho a la desconexión digital de los empleados, así como el derecho a la conciliación de su vida familiar y laboral e intimidad, lo que se traduce en la consideración de una infracción grave de la normativa laboral, sancionada con multas en atención a su grado (por ejemplo número de trabajadores a los que se les ha vulnerado su intimidad con mensajes indiscriminados) que pueden ir, en un grado mínimo, de 626 a 1.250 euros, en un grado medio de 1.251 a 3.125 euros; y en un grado máximo de 3.126 hasta 6.250 euros

producirse por la ausencia o deficiencia de las medidas preventivas necesarias. d) El número de trabajadores afectados. e) Las medidas de protección individual o colectiva adoptadas por el empresario y las instrucciones impartidas por éste en orden a la prevención de los riesgos. f) El incumplimiento de las advertencias o requerimientos previos a que se refiere el artículo 43 de la LPRL. $g$ ) La inobservancia de las propuestas realizadas por los servicios de prevención, los delegados de prevención o el comité de seguridad y salud de la empresa para la corrección de las deficiencias legales existentes. h) La conducta general seguida por el empresario en orden a la estricta observancia de las normas en materia de prevención de riesgos laborales".

${ }^{37}$ Recargo que soporta el empleador y que favorece al trabajador lesionado. Según el artículo 64 LGSS: "todas las prestaciones económicas que tengan su causa en accidente de trabajo o enfermedad profesional se aumentarán, según la gravedad de la falta, de un 30 a un 50 por ciento, cuando la lesión se produzca por equipos de trabajo o en instalaciones, centros o lugares de trabajo que carezcan de los medios de protección reglamentarios, los tengan inutilizados o en malas condiciones, o cuando no se hayan observado las medidas generales o particulares de seguridad y salud en el trabajo, o las de adecuación personal a cada trabajo, habida cuenta de sus características y de la edad, sexo y demás condiciones del trabajador. La responsabilidad del pago del recargo establecido en el apartado anterior recaerá directamente sobre el empresario infractor y no podrá ser objeto de seguro alguno, siendo nulo de pleno derecho cualquier pacto o contrato que se realice para cubrirla, compensarla o trasmitirla. La responsabilidad que regula este artículo es independiente y compatible con las de todo orden, incluso penal, que puedan derivarse de la infracción". 
[artículo 40 b) LISOS]. Y adicionalmente según el caso esta irregularidad puede ser considerada también como infracción muy grave por situación de acoso laboral conforme a los artículos 8.13 y 8.13-bis de a LISOS con una multa económica aparejada, en su grado mínimo, de 6.251 a 25.000 euros; en su grado medio de 25.001 a 100.005 euros; y en su grado máximo de 100.006 euros a 187.515 euros. Respecto a los preceptos de acoso tipificados como muy grave: "13. El acoso sexual, cuando se produzca dentro del ámbito a que alcanzan las facultades de dirección empresarial, cualquiera que sea el sujeto activo de la misma (...) 13 bis. El acoso por razón de origen racial o étnico, religión o convicciones, discapacidad, edad y orientación sexual y el acoso por razón de sexo, cuando se produzcan dentro del ámbito a que alcanzan las facultades de dirección empresarial, cualquiera que sea el sujeto activo del mismo, siempre que, conocido por el empresario, éste no hubiera adoptado las medidas necesarias para impedirlo" cabe la duda de que la conducta de la empresa por la que no garantiza el derecho a la desconexión digital se incardine en una situación de acoso. La duda de esta tipificación estriba en si es contraria o no al principio de tipicidad y prohibición de la analogía tal y como regula el artículo 27.4 de la Ley 40/2015, de Régimen Jurídico del Sector Público (BOE, 2 de oct. 2015) en el momento en que se imponen las sanciones administrativas.

No obstante lo anterior, no resultaría descabellado en atención lo señalado con anterioridad, el surgimiento de conductas propias de ciberacoso (network mobbing ${ }^{38}$ ) que

\footnotetext{
${ }^{38}$ A través del ciberacoso en el trabajo, se producen conductas agresivas llevadas a cabo bajo el paraguas de las TIC, y puede incluir imágenes/videoclips, correos electrónicos o sitios de redes sociales, entre otros. En efecto, bajo este fenómeno, el trabajador puede sufrir situaciones de hostigamiento, por medio de múltiples canales digitales: teléfono móvil — por medio de programas de mensajería instantánea o llamadas-, ordenadores - a través de programas de videoconferencias como muchas otras, Skype o Zoom - o bien, directamente, a través de correos electrónicos profesionales. En estos casos se hace más que necesaria la desconexión fuera del horario del trabajo por lo que son totalmente inaceptables - salvo casos de fuerza mayor - no solo mensajes con contenido laboral sino, obviamente, también con contenido vejatorio u hostigador. A este propósito, el citado Convenio 190 OIT, el cual existe la previsión de que sea ratificado por España, se aplica a todo tipo de trabajador ante situaciones laborales de violencia y acoso que ocurren durante el trabajo, en relación con el trabajo o como resultado del mismo y, entre otras situaciones, por lo que aquí interesa: "d) en el marco de las comunicaciones que estén relacionadas con el trabajo, incluidas las realizadas por medio de tecnologías de la información y de la comunicación" (artículo 3). En términos prácticos y legales (ex LPRL y RSP), la empresa ha de evaluar estos factores de riesgos psicosociales para contrarrestarlos y acatarlos bien desde su génesis, bien una vez las actuaciones de violencia se están desarrollando. Igualmente, sobre el "ciberacoso" que sin duda se trata de un fenómeno laboral relativamente reciente e inexplorado, existe un documento reciente publicado por la OIT (2020, 13 de febrero) que, de forma amplia y rigurosa, examina las fuentes legales en torno al "ciberacoso" en el mundo del trabajo; revisa las medidas adoptadas en los países para contrarrestar el acoso y analiza cómo podrían utilizarse para abordar también el "ciberacoso". El estudio concluye con sugerencias preliminares sobre las posibles formas de contrarrestarlo. Atinente a las formas de contrarrestarlos, son de buen recibo la redacción de posibles declaraciones de principios que, de antemano, sirven para que ambas partes de la
} 
ha sido objeto de amplio estudio por la doctrina iuslaboralista española ${ }^{39}$ acentuado por la publicación del Convenio sobre la violencia y el acoso, 2019 (núm. 190) de la OIT ${ }^{40}$ y de la Recomendación (núm. 206) que lo complementa.

La iniciativa legislativa finaliza con sus artículos 9 a $14^{41}$, generales y propios de toda Directiva.

relación laboral (empresa y trabajador) sean conocedoras de los riesgos y del efecto que puede tener sobre la dignidad.

39 Vid. entre otros: Molina NAVARRETE, Cristóbal, "Del acoso moral ("mobbing") al ciberacoso en el trabajo ("network mobbing") viejas y nuevas formas de violencia laboral como riesgo psicosocial en la reciente doctrina judicial. Estudios financieros", Revista de trabajo y seguridad social: Comentarios, casos prácticos: recursos humanos, ISSN 1138-9532, no 437-438, 2019, p. 143-165.; DE VICENTE PACHÉS, Fernando, "Las facultades empresariales de vigilancia y control en las relaciones de trabajo: concepto y fundamento. Una primera aproximación a las diversas formas de control empresarial", en GARCÍA NINET, Ignacio, (Dir.) y DE VICENTE PACHÉs, Fernando, (Coord.), El control empresarial en el ámbito laboral, Valencia, CISS, 2005, p. 17-47; DE VICENTE PACHÉS, Fernando, "El Convenio 190 OIT y su trascendencia en la gestión preventiva de la violencia digital y ciberacoso en el trabajo", Revista de Trabajo y Seguridad Social. CEF (RTSS. CEF), nº 488, p. 69-106 y DE VICENTE PACHÉs, Fernando, Ciberacoso en el trabajo, Barcelona, Atelier, 2018.

${ }^{40} \mathrm{El}$ cual, entrará en vigor el 25 de junio de 2021. Dado que es requisito que al menos dos Estados miembros de la OIT, 12 meses antes, lo hayan ratificado. A fecha del presente libro lo han hecho los países Uruguay (ratificado a fecha 12 de junio 2020) y Fiji (ratificado a fecha 25 de junio de 2020).

41 "Artículo 9 Nivel de protección

1. La presente Directiva no constituirá un motivo válido para reducir el nivel general de protección ya concedido a los trabajadores en los Estados miembros.

2. La presente Directiva no afectará a la prerrogativa de los Estados miembros de aplicar o introducir disposiciones legales, reglamentarias o administrativas más favorables para los trabajadores o de fomentar o permitir la aplicación de convenios colectivos más favorables para los trabajadores.

3. La presente Directiva se entiende sin perjuicio de cualesquiera otros derechos conferidos a los trabajadores por otros actos jurídicos de la Unión.

Artículo 10 Informe, evaluación y revisión del derecho a desconectarse

1. A más tardar ... [cinco años después de la entrada en vigor de la presente Directiva] y, a partir de entonces, cada dos años, los Estados miembros presentarán a la Comisión un informe con toda la información pertinente sobre la aplicación práctica y la aplicación de la presente Directiva, así como indicadores de evaluación sobre las prácticas de implementación del derecho a la desconexión, indicando los respectivos puntos de vista de los interlocutores sociales nacionales.

2. Sobre la base de la información facilitada por los Estados miembros de conformidad con el apartado 1, la Comisión, a más tardar ... [seis años después de la entrada en vigor de la presente Directiva] y posteriormente cada dos años, presentará un informe al Parlamento Europeo. y al Consejo sobre la implementación y aplicación de la presente Directiva y considerar la necesidad de medidas adicionales, incluidas, cuando proceda, modificaciones de la presente Directiva.

Artículo 11 Transposición

1. A más tardar... [dos años después de la entrada en vigor de la presente Directiva], los Estados miembros adoptarán y publicarán las medidas necesarias para cumplir la presente Directiva. Informarán de ello inmediatamente a la Comisión. 


\section{Conclusiones}

La iniciativa del Parlamento Europeo surge empujada por el contexto actual de la COVID-19 donde muchos trabajadores comunitarios han incrementado sus horas de trabajo durante la pandemia por no desconectar sus dispositivos digitales durante los tiempos de descanso. Tanto es así que desde el EUROFOUND ${ }^{42}$, quienes trabajan regularmente desde casa tienen más del doble de probabilidades de trabajar más del requisito máximo de 48 horas por semana y corren el riesgo de descansar menos de las 11 horas requeridas entre días laborables.

Los eurodiputados ponen así de relieve una realidad palpable a día de hoy y que se ha refrendado meses después de la utilización masiva de la modalidad del trabajo a distancia a nivel mundial: la digitalización y el uso de las TIC aportan muchos beneficios y ventajas económicas y sociales (mayor autonomía y flexibilidad para el trabajador) pero, por el contrario, la abusiva utilización de los medios digitales provoca desventajas en forma de

Aplicarán dichas medidas a partir de... [tres años después de la fecha de entrada en vigor de la presente Directiva].

Cuando los Estados miembros adopten dichas disposiciones, estas incluirán una referencia a la presente Directiva o irán acompañadas de dicha referencia en su publicación oficial. Los Estados miembros establecerán los métodos para hacer tal referencia.

2. Tan pronto como la presente Directiva entre en vigor, los Estados miembros se asegurarán de que se informe a la Comisión, con tiempo suficiente para que presente sus comentarios, de cualquier proyecto de ley, reglamento o disposición administrativa que se proponga adoptar en el ámbito cubierto. por esta Directiva.

3. De conformidad con el artículo 153, apartado 3, del TFUE, los Estados miembros podrán encomendar a los interlocutores sociales, a petición conjunta, la aplicación de la presente Directiva, siempre que garanticen el cumplimiento de la presente Directiva.

Artículo 12 Información personal

Los empleadores tratarán los datos personales de conformidad con el artículo 4, apartado 1, letras a) y b), de la presente Directiva únicamente con el fin de registrar el tiempo de trabajo de un trabajador individual. No procesarán dichos datos para ningún otro propósito. Los datos personales se procesarán de conformidad con el Reglamento (UE) 2016/679 del Parlamento Europeo y del Consejo. (19) y la Directiva 2002/58 / CE del Parlamento Europeo y del Consejo. (20).

Artículo 13 Entrada en vigor

La presente Directiva entrará en vigor el vigésimo día siguiente al de su publicación en el Diario Oficial de la Unión.

Artículo 14 Destinatarios

Los destinatarios de la presente Directiva serán los Estados miembros.

Hecho ...,

Por el Parlamento Europeo".

${ }^{42}$ Vid. VARGAS LLAVE, Oscar et. al. (2020). Telework and ICT-based mobile work: Flexible working in the

digital age, recuperado de:

https://www.eurofound.europa.eu/sites/default/files/ef_publication/field_ef_document/ef19032en.pdf

[Consulta a 13 de marzo de 2021]. 
mayores cargas de trabajo y de horas efectivas de empleo (difuminando así los tiempos de trabajo con los de ocio y descanso) que han de ser solventadas desde la ética y la legalidad.

El texto de borrador de Directiva patentiza un déficit normativo importante en la Unión Europea dado que no existe una normativa propia y explícita sobre el derecho del trabajador a desconectarse de las herramientas digitales, incluidas las TIC, por motivos laborales. Uno de los fines del borrador presentado es el de equilibrar las fuerzas de la relación laboral, evitando de este modo que el empresario no explote a su propio beneficio económico el desempeño de los trabajadores mediante el uso abusivo de las herramientas digitales y el teletrabajo. Con los requisitos mínimos determinados en el texto de la iniciativa para garantizar el ejercicio de la desconexión digital en el trabajo, se pretende respetar todo aquello que imbrica con el ejercicio del derecho, es decir, una retribución justa, un límite al tiempo de trabajo y, en consecuencia, la consecución de un equilibrio en la conciliación laboral y personal del trabajador, una igualdad efectiva entre hombres y mujeres (la Directiva acierta al señalar que la perspectiva de género ha de ser valorada en la redacción de políticas internas) y una mejora de las condiciones de seguridad y salud que, como se ha señalado, la falta de desconexión digital tiene una afectación clara a la salud física y mental del trabajador.

Destacable es su apartado relativo a la consideración del derecho como fundamental dado que, según el texto, el derecho a la desconexión digital "(...) forma parte inseparable de los nuevos modelos de trabajo en la nueva era digital'. En consecuencia, la iniciativa, en su borrador, reconoce una amplia protección del derecho admitiendo la consideración del mismo como fundamental, eso sí, sin obstar a las excepciones particulares tal y como, sucede en España con muchos convenios colectivos que, ante casos de urgencia, el derecho puede quedar invalidado. Ahora bien, a nivel comunitario, ante estos casos en los que el derecho desaparece, la empresa ha de comunicar al trabajador y de forma motivada los motivos y razones que empujan a esta invalidez; en definitiva, situaciones con carácter de urgencia y de emergencia. Igualmente, el trabajador tiene protección ante estos casos dado que la compensación económica será tenida en cuenta con carácter previo a estas situaciones.

La iniciativa legislativa no escatima esfuerzos en proteger a todos los trabajadores (privados y públicos) y con independencia de su modalidad contractual; no solo aquellos que presten servicios a distancia -quienes, desde luego, cuentan con más probabilidades de realizar más horas de trabajo- sino los que están empleados en centros de trabajo físicos. Igualmente, define claramente el derecho a la desconexión digital lo que aporta una determinación y seguridad jurídica. 
También, como se ha analizado en líneas precedentes, el texto protege al trabajador que pueda sufrir represalias o perjuicios en sus condiciones laborales (promoción profesional, incentivos, etc.) por ejercer el derecho. El texto aboga, atinadamente, por un régimen sancionador que sea efectivo, proporcionado y disuasorio ante situaciones en las que la empresa transgreda el derecho a la desconexión tecnológica del trabajador. Circunstancia que, como es sabido, no sucede en España, dado que no existe en la LISOS una infracción concreta y explícita que tipifique irregularidades propias de desconexión digital; sí que se pueden relacionar otras, de forma indirecta, dirigiendo estas conductas dentro del cajón de los incumplimientos en los tiempos de trabajo.

Así mismo, obliga a las empresas a que canalicen medios de información sobre el mismo y determinen junto con la representación legal de trabajadores políticas internas o protocolos de actuación que modulen el derecho. Del mismo modo, han de quedar anuladas toda norma empresarial que determine recompensas o mejores ventajas para el trabajador que no desconecte. En línea con esta falta de desconexión que tiene implicaciones muy serias desde la seguridad y salud en el trabajo, en términos de prevención de riesgos laborales, el derecho a la desconexión digital a nivel comunitario ha de ser regulado de forma que se exija a los empleadores cuidar la salud de sus trabajadores; la pandemia ha sacado a la luz problemas muy graves desde aislamiento social y profesional, hasta fatiga física y mental, ansiedad, depresión y dolores musculoesqueléticos. Todo por el incremento de horas de trabajo y el uso excesivo de los dispositivos digitales.

Frente a estas recomendaciones analizadas en el artículo sobre el derecho a la desconexión digital, habrá que estar a la expectativa, dado que de emitirse la Directiva obligaría a los Estados miembros a trasponer en el plazo que así determine el derecho a desconectarse en el ordenamiento jurídico interno. Se trata de un texto que reviste la forma de borrador por lo que no será el definitivo. Sin duda, mientras se cristaliza esta opción, los Gobiernos han de adoptar todas las medidas y políticas para que se garanticen los descansos de los trabajadores. España deberá concretar mejor el derecho, estableciendo sucintamente, mayores concreciones informativas para los trabajadores, los mecanismos de tutela y el régimen sancionador. En este terreno, tanto la reforma de la actual regulación del derecho laboral que, eventualmente se pueda producir en España, como también la futura Directiva han de reforzar los mecanismos de tutela para que los trabajadores puedan disfrutar de este derecho laboral y no puedan sufrir represalias y ser victimizados por invocarlo. Para la eficacia y garantía de este mecanismo de protección se debería incluir la inversión de la carga de la prueba, para que, si un trabajador es victimizado por invocar este derecho, sea el empresario quien deba demostrar que no fue así. 
Sea como fuera, gracias a la eventual Directiva que tiene más luces que sombra habida cuenta del análisis anterior, muchos países comunitarios que siguen sin contar con regulación específica deberán hacerlo en el plazo indicado. Estos países, siguiendo la estela de la eventual Directiva deberán promover el derecho siempre en conjunción con los agentes sociales mediante la inclusión en los convenios colectivos. En definitiva, todo aquello para que los trabajadores comunitarios puedan ejercer este derecho a la desconexión digital sin temor a que sean discriminados, criticados, despedidos u objeto de represalias de ningún tipo por ejercerlo. Desde este prisma, como se ha afirmado, los trabajadores que sientan que han sido tratados negativamente por su deseo de desconectarse después del trabajo podrán presentar todo tipo de pruebas a los tribunales laborales o autoridades públicas (como en España ante la ITSS) quienes deberán acogerlas para dar lugar a una presunción de que efectivamente esa fue la razón de su mal trato. Obviamente, la carga de la prueba corresponderá al empleador que deberá demostrar que el tratamiento negativo se basó en otros motivos.

\section{Bibliografía}

Altés TÁRREGA, Juan Antonio y Yagüe Blanco, Sergio, “A vueltas con la desconexión digital eficacia y garantías de lege lata", Labos: Revista de Derecho del Trabajo y Protección Social, 1(2), 2020, p. 61-87.

ARRIETA IDIAKEZ, Francisco Javier, "La desconexión digital y el registro de la jornada diaria en España como mecanismos para garantizar el descanso, la salud y el bienestar de los trabajadores digitales a distancia", Lan harremanak: Revista de Relaciones Laborales, $n^{\circ} 42,2019$.

De Vicente PAChÉS, Fernando, "El Convenio 190 OIT y su trascendencia en la gestión preventiva de la violencia digital y ciberacoso en el trabajo", Revista de Trabajo y Seguridad Social. CEF (RTSS. CEF), n 488, p. 69-106.

DE VICENTE PACHÉS, Fernando, "Las facultades empresariales de vigilancia y control en las relaciones de trabajo: concepto y fundamento. Una primera aproximación a las diversas formas de control empresarial", en GARCíA NINET, Ignacio (Dir.) y DE VICENTE PACHÉs, Fernando (Coord.), El control empresarial en el ámbito laboral, 2005, Valencia, CISS, p. 17-47.

De Vicente Pachés, Fernando, Ciberacoso en el trabajo, Barcelona, Atelier, 2018.

Domingo Monforte, José, y SAlvador Álvarez, Neus, "Hiperconectividad digital y salud laboral", Diario La Ley, nº 9638, 2020. 
ESCRICHE RIVAS, Elisabet, “L'Estat sanciona 2.000 empreses per incomplir la jornada laboral", Ara.cat. Recuperado de: https://m-aracat.cdn.ampproject.org/c/s/m.ara.cat/economia/estat-sanciona-2000-empresesincomplir-jornada-laboral-crisi-sanitaria-coronavirus-COVID19_0_2544345563.amp.html [Consulta a 14 de octubre 2020].

European Parliament, DRAFT OPINION of the Committee on Employment and Social Affairs for the Committee on Industry, Research and Energy on a New Industrial Strategy for Europe (2020/2076(INI)) Rapporteur for opinion: Jordi Cañas, recuperado de: https://www.europarl.europa.eu/doceo/document/EMPL-PA-652607_EN.pdf

[Consulta a 17 de junio 2020].

European Parliament, European Parliament resolution of 21 January 2021 with recommendations to the Commission on the right to disconnect (2019/2181(INL)), recuperado de: https://www.europarl.europa.eu/doceo/document/TA-9-20210021_EN.html\#title1 [Consulta a 9 de marzo 2020].

Instituto Nacional de Estadística (INE), Número total de horas extraordinarias realizadas en la semana por todos los asalariados por sexo y ocupación 2020-T2, recuperado de: https://www.ine.es/jaxiT3/Datos.htm?t=4366\#!tabs-tabla [Consulta a 2 de junio 2020].

Molina NavarRete, Cristóbal, "Del acoso moral ("mobbing") al ciberacoso en el trabajo ("network mobbing") viejas y nuevas formas de violencia laboral como riesgo psicosocial en la reciente doctrina judicial. Estudios financieros", Revista de trabajo y seguridad social: Comentarios, casos prácticos: recursos humanos, $\mathrm{n}^{\circ}$ 437-438, 2019, p. 143-165.

Netrisk, Registro horario: estar conectado al ordenador se considera tiempo trabajado. Entrad en Netrisk, recuperado de: https://netriskprevencion.com/Registro-horario-estarconectado-al-ordenador-se-considera-tiempo-trabajado-14 [Consulta a 14 julio de 2020].

Reche Tello, Nuria, "La Desconexión digital como límite frente a la invasión de la privacidad", IUSLabor Revista d'anàlisi de Dret del Treball, [en línea], 2019, nº 3, p. 3154, https://www.raco.cat/index.php/IUSLabor/article/view/362118 [Consulta: 4-6-2020].

Sebastián García, Olga, y Del Hoyo Delgado, María Ángeles, La carga mental del trabajo, Instituto Nacional de Seguridad e Higiene en el Trabajo Composición e impresión: Servicio de Ediciones y Publicaciones INSHT, 2016, Madrid, p. 16. https://www.insst.es/documents/94886/96076/carga+mental+de+trabajo/2fd91b55f191-4779-be4f-2c893c2ffe37 [Consulta a 2 junio 2020]. 
SERrAno ArgüEso, Mariola, ““Always on”, Propuestas para la efectividad del derecho a la desconexión digital en el marco de la economía 4.0". Revista Internacional y Comparada de Relaciones Laborales y Derecho del Empleo, no 7, vol. 2, 2019, p. 164191.

Serrano Olivares, Raquel y Sabaté CAnelles, Mireia, "Los derechos a la desconexión digital y al registro de la jornada”, Revista jurídica de Catalunya, vol. 118, 2019.

Trujillo Pons, Francisco y Toscani Giménez, Daniel, La desconexión digital en el trabajo, Aranzadi Thomson Reuters y Universidad de Valencia, 2020.

TRUJILlo PONS, Francisco, "La importancia de la comunicación interna en PRL", Gestión práctica de riesgos laborales: Integración y desarrollo de la gestión de la prevención, $\mathrm{n}^{\mathrm{o}}$ $166,2019$.

TRUJILlo Pons, Francisco, La desconexión digital en el ámbito laboral, Valencia, Tirant lo Blanch, 2020.

VARGAS LLAVE, Oscar et. al. Telework and ICT-based mobile work: Flexible working in the digital age, https://www.eurofound.europa.eu/sites/default/files/ef_publication/field_ef_document/e f19032en.pdf [Consulta a 13 de marzo de 2021]. 